\title{
PRESIDEN JOKO WIDODO DALAM BINGKAI MEDIA MASSA
}

\author{
Suharyo, Surono, dan M.Farikhul.A. \\ Fakultas Ilmu Budaya Universitas Diponegoro \\ email: haryo.sastra@gmail.com
}

\begin{abstract}
Abstrak
Penelitian ini bertujuan untuk mendeskripsikan ideologi (a) wartawan, (b) politisi, dan (c) pengamat/masyarakat dalam mem-frame Presiden Joko Widodo di media massa. Sumber data penelitian ini adalah harian Suara Merdeka, Kompas, dan Republika yang terbit tahun 2016. Pengumpulan data dilakukan dengan (a) studi pustaka, (b) analisis wacana, dan (c) wawancara mendalam terhadap pakar linguistik dan media massa. Analisis data dilakukan dengan menggunakan analisis framing model Pan dan Kosicki. Hasilnya adalah terdapat perbedaan ideologi di antara ketiga media tersebut dalam mem-frame Presiden Joko Widodo. Hal itu terlihat pada perbedaan dalam aspek (a) sintaksis, (b) skrip, (c) tematik. (d) dan retoris. Ketiga media juga berbeda dalam menyusun: (a) skema berita, (b) kelengkapan berita, (c) detail, (d) leksikon, dan (e) kelengkapan unsur 5W+1 H dalam memberitakan Presiden Joko Widodo.
\end{abstract}

Kata kunci:frame, ideologi, media, analisisframing

\section{PRESIDENT JOKO WIDODO IN THE FRAME OF MASS MEDIA}

\begin{abstract}
This study aimed to describe the ideology of: (a) journalists, (b) politicians, and (c) observers/community in framing President Joko Widodo in Suara Merdeka, Kompas, and Republika daily newspapers. The data sources were the three newspapers published in 2016. The data were collected through: (a) literature study, (b) discourse analysis, and (c) in-depth interviews with linguists and mass media experts. The data analysis was carried out using Pan and Kosicki's framing analysis model. The results show that there are ideological differences among the three media in framing President Joko Widodo. The differences are manifested in the aspects of: (a) syntax, (b) script, (c) theme, and (d) rhetoric. The three media also differ in presenting: (a) news schemes, (b) news completeness, (c) details, (d) lexicon, and (e) completeness of $5 \mathrm{~W}+1 \mathrm{H}$ elements in reporting President Joko Widodo.
\end{abstract}

Keywords: frame, ideology, media, framing analysis

\section{PENDAHULUAN}

Independen dan objektif merupakan dua kata kunci yang menjadi kiblat dan klaim setiap jurnalis di seluruh dunia (Eriyanto, 2012: 15-21; 43-51). Hal ini menunjukkan bahwa kerja jurnalis bersikap objektif dan tidak memihak sesuai dengan prinsip jurnalistik, seperti (a) kewajiban jurnalis (wartawan/redaksi) terhadap kebenaran, (b) loyalitas media adalah pada masyarakat, (c) harus menjaga independensi terhadap sumber berita, (d) harus menyiarkan berita secara komprehensif dan proporsional, dan (e) wartawan/redaksi harus mempunyai etika dan tanggung jawab sosial (Irfan, 2011). Kondisi normatif ini tampaknya memang dijumpai pada era ORBA. Akan tetapi, 
pada era Orde Reformasi seperti sekarang rasanya sulit dijumpai berita di media massa yang objektif dan independen. Lihatlah, misalnya pemberitaan di TV One, Metro TV, RCTI, dan MNCTV sewaktu masa Pilpres 2014, serta media massa seperti Suara Merdeka, Kompas, Kedaulatan Rakyat, Tribune, Jawa Pos, Republika, Obor Rakyat sebagaimana hasil penelitian Lukmantoro (2011).

Menurut hasil penelitian Irfan, 2011; Hasfi, 2011; Putera, 2014; Rachanca, 2012; Windranuari, 2010; Atmadja, 2014; Flora, 2014; ditemukan bahwa berita di media massa sudah dikontruksi sedemikan rupa sebagai komoditas politik, ekonomi, dan sosial budaya. Lebih jauh dikemukakan bahwa realitas bukanlah "fakta yang sebenarnya", tetapi sudah di-frame oleh penulis (wartawan/redaksi) sesuai dengan kepentingan tertentu (ideologi, politik, ekonomi). Pembaca, tanpa disadari telah "digiring" untuk memahami realitas yang telah dibingkai oleh media massa. Dan pemahaman terhadap realitas tersebut tergantung media massa mana yang membingkainya. Jadi, sesungguhnya ia (pembaca) telah "terperangkap" oleh pola konstruksi media massa (lihat Muslich, 2008). Sekedar contoh di harian Kompas ditulis judul "Lee Kuan Yew Wariskan Singapura yang Maju", tetapi di harian Suara Merdeka "Lee KuanYewTerapkan Tangan Besi, Miliki Kesamaan dengan Soeharto". Realitas semacam ini sejalan dengan pandangan linguistik kritis bahwa pilihan bahasa dibuat menurut seperangkat kendala politis, sosial, kultural, dan ideologi. Jadi, (a) pilihan bahasa bukan menjadi pilihan individu, tetapi diproduksi oleh interaksi dan komunikasi yang ditentukan secara ideologis dan politis; (b) teks sebagai realisasi modus wacana, artinya bahwa bukan hanya karya individual, tetapi mungkin saja oleh orang lain yang semuanya berakar pada kondisi sosial, politis, ekonomi, dan ideologis. Jadi, sistem bahasa merupakan bagian integral dari struktur dan proses sosial; (c) bahasa sebagai alat untuk mengategorikan realitas kehidupan (Darma, 2013: 45-48; Lee, 2002).

Melihat paparan diatas menjadi menarik untuk dikaji bagaimanakah media massa dalam mengemas dan menyajikan berita di era Orde Reformasi seperti sekarang ini terutama berita tentang Pemerintahan Joko Widodo? apakah objektif, independen, dan mono interpretasi sebagaimana pandangan positivisme? Atau justru sebaliknya, yaitu subjektif dan berpihak sebagaimana pandangan konstruksionis? lalu apakah antara satu media massa dengan media massa lainnya dalam menyampaikan isi berita tersebut sama ? Bagaimana pula redaksi/ wartawan dalam menggali, memilih, dan menentukan informasi, fakta, memilih nara sumber, pengamat, dan bahkan masyarakat sebagai bahan dan sumber beritanya? Secara ringkas tulisan ini akan menguraikan konstruksi realitas Presiden Joko Widodo oleh tiga media massa (Suara Merdeka, Republika, dan Kompas) melalui analisis framing.

Muslich (2008) menjelaskan bahwa betapa besar kekuasaan media massa mengonstruksi realitas. Setiap hari, kita disuguhi berita hasil konstruksi media. Anehnya, dunia yang kita lihat sekarang ini sering kita anggap sebagai dunia yang sebenarnya. Semua berita "semu" tersebut sesungguhnya adalah hasil dari frame (ing) media massa.

Karman (2013) dalam penelitiannya mengemukakan bahwa masalah Ahmadiyah bagi Suara Pembaruan adalah persoalan HAM/kebebasan beragama, sedangkan Republika mem-frame bahwa kegiatan Ahmadiyah sebagai penistaan, pelecehan, penyimpangan, serta penodaan terhadap pokok-pokok ajaran Islam. Irfan menyebutkan tentang keberpihakan Kompas terhadap RUUK-DIY melalui penetapan sangat tampak (Irfan, 2011). Penelitian lainnya dilakukan oleh Pamela 
Prastyana (2013) yang menyimpulkan pada Harian Umum Solopos jika dilihat dari pandangan pengelola media, Joko Widodo mempunyai nilai berita yang tinggi karena memenuhi beberapa unsur kelayakan berita, antara lain penting, besaran, dekat, manusiawi, ketenaran dan juga kontroversi. Solopos secara umum selalu menyajikan informasi yang berimbang, akurat dan unggul.

Menurut hasil penelitian Irfan, 2011; Hasfi, 2011; Putera, 2014; Rachanca, 2012; Windranuari, 2010; Atmadja, 2014; Flora, 2014; di atas secara ringkas dikemukakan bahwa berita di media massa sudah dikontruksi sedemikan rupa sebagai komoditas politik, ekonomi, dan sosial budaya. Lebih jauh dikemukakan bahwa realitas bukanlah "fakta yang sebenarnya", tetapi sudah di-frame oleh penulis (wartawan/redaksi) sesuai dengan kepentingan tertentu (ideologi, politik, ekonomi). Pembaca, tanpa disadari telah "digiring" untuk memahami realitas yang telah dibingkai oleh media massa. Dan pemahaman terhadap realitas tersebut tergantung media massa mana yang membingkainya. Jadi, sesungguhnya ia (pembaca) telah "terperangkap" oleh pola konstruksi media massa (lihat Muslich, 2008).

Analisis framing adalah suatu metode (analisis) untuk mengetahui bagaimana realitas (peristiwa, aktor, kelompok, dll.) dibingkai oleh media melalui konstruksi. Lalu, realitas sosial dimaknai dan dikonstruksi dengan makna tertentu. Misal, hak angket yang diajukan oleh DPRD DKI Jakarta dapat dimaknai sebagai kontrol dari legislatif terhadap Ahok, tetapi bisa juga dimaknai sebagai "upaya menjatuhkan" Ahok.

Karakteristik Analisis Framing sebagai berikut. Pertama, fakta atau peristiwa merupakan hasil konstruksi sehingga realitas itu bersifat subjektif. Realitas itu hadir karena dikontruksi oleh wartawan. Kedua, media merupakan agen konstruksi sosial yang mendefinisikan realitas lengkap dengan pandangan, bias, dan pemaknaannya. Ketiga, media bukan refleksi dari suatu realitas, tetapi ia hanya kontruksi dari realitas seperti layaknya sebuah drama. Keempat, berita bersifat subjektif sebab berita pada dasarnya produk dari suatu kontruksi dan pemaknaan atas realitas. Kelima, wartawan bukan pelapor, tetapi agen konstruksi realitas. Berita bukanlah cerminan dari suatu realitas, melainkan berita merupakan "hasil rekayasa dan pemaknaan" wartawan. Keenam, etika, nilai, pilihan moral, keberpihakan wartawan merupakan bagian integral dalam produksi berita. Ketujuh, khalayak pembaca memiliki penafsiran sendiri terhadap berita.

Ideologi adalah sebuah sistem nilai atau gagasan yang dimiliki oleh kelompok/lapisan masyarakat tertentu dalam produksi makna dan gagasan (Darma, 2013:56). Implikasi dari praktik ideologi memunculkan hegemoni dan legitimasi melalui penciptaan "kesepakatan semu", seperti peristiwa/realitas yang "dibungkus" dalam bentuk opini, kelompokkelompok moral, parlemen.

Hallin (1985) menjelaskan bahwa sebuahperistiwa hanya akan berarti jika ia ditempatkan dalam identifikasi kultural tempat berita tersebut hadir, sehingga pada dasarnya wartawan menempatkan peristiwa ke dalam peta makna (kognitif masyarakat, seperti kategorisasi, identifikasi sosial, dan kontekstualisasi). Media, dalam hal ini lalu berperan mendefinisikan bagaimana realitas seharusnya dipahami dan bagaimana realitas dijelaskan dengan cara (pandang) tertentu kepada khalayak pembaca. Misal suatu berita akan ditempatkan pada bidang/ peta ideologi ke dalam (a) bidang penyimpangan (misal, tentang PKI), (b) bidang kontroversi (misal, LGBT), dan (c) bidang consensus (misal, kemakmuran rakyat). Bidang-bidang tersebut menjelaskan bagaimana peristiwa-peristiwa dipahami dan ditempatkan oleh wartawan dalam 
keseluruhan peta ideologis. Sebagai area ideologis, peta semacam ini dapat dipakai untuk menjelaskan bagaimana perilaku dan realitas yang sama dapat diberitakan secara berbeda (Eriyanto, 2012: 141-160).

Dalam pandangan positivisme, media massa sebagai alat penyaluran pesan. Media massa sebagai alat yang netral. Namun, kaum konstruksionis berpandangan lain, yaitu bahwa media massa bukan hanya sebagai penyalur/penyampe pesan, tetapi ia juga sebagai subjek yangmengontruksi realitas, berikut pandangan, bias, dan pemihakannya (Muslich, 2008). Dalam hal ini, media massa dipandang sebagai agen kontruksi sosial yang mendefinsikan realitas. Bagiamana halnya dengan wartawan? Bagi penganut positivistik, wartawan adalah penyampai berita yang mencerminkan realitas, dan wartawan yang baik adalah sesorang yang mampu memindahkan realitas kedalam berita.Sementara, kaum konstruksionis wartawan adalah seorang agen konstruksi yang tidak hanya melaporkan tetapi juga terlibat dalam pendefinsian fakta/peristiwa. Konsekuensinya, etika, pilihan moral, dan keberpihakan wartawan merupakan bagian yang integral dan inheren dalam produksi berita (Muslich, 2008).

\section{METODE}

Penelitian ini mengambil sumber data Kompas, Republika, dan Suara Merdeka yang terbit pada tahun 2016. Alasan pengambilan sumber data dari media cetak karena (1) sesuai karakteristik penelitian yang menggunakan pendekatan framing. Dipilihnya Kompas, Republika, dan Suara Merdeka dengan alasan: (1) mewakili koran yang berskala nasional (Kompas dan Republika) dan lokal (Suara Merdeka), (2) ketiganya beroplah cukup besar, dan (3) memiliki jangkauan pembaca dan daerah persebaran yang cukup luas, (4) ketiga media tersebut dihipotesiskan memiliki ideologi yang berbeda.
Pengumpulan data dilakukan dengan metode simak dilanjutkan dengan teknik catat. Metode simak dilakukan dengan cara (1) membaca dengan cermat wacana/ teks berita di tiga media massa (Suara Merdeka, Kompas, dan Republika) yang memuat pemberitaan tentang pemerintahan/ Presiden Joko Widodo (2) meneliti aspek struktur bahasanya (pilihan kata, kosa kata, kalimat, koherensi, aspek nalar, dan lain-lain), (3) mencermati hal-hal penting yang berupa konstruksi realitas pemerintahan/Presiden Joko Widodo.

Dalam penelitian/tulisan ini, data dianalisis dengan menggunakan metode analisis framing model Pandan Kosicki seperti ditunjukkan lewat bagan 1 (Eriyanto, 2012: 295).

\section{HASIL DAN PEMBAHASAN}

Sesuai dengan tujuan penelitian, deskripsi pemberitaan "Pencapresan Joko Widodo pada 2019" bersumber dari tiga media, yaitu Kompas, Republika, dan Suara Merdeka. Deskripsi terperinci disajikan pada sub-subbagian berikut.

\section{Frame Pencapresan Joko Widodo oleh Harian Suara Merdeka}

Harian Suara Merdeka (SM) memaknai dukungan Golkar terhadap pencapresan Joko Widodo sebagai "ancaman" terhadap posisi/dukungan partai-partai yang tergabung dalam Koalisi Indonesia Hebat (KIH). Hal ini dengan jelas, Suara Merdeka hanya mengambil sumber berita dari Jazilul Fawaid sebagai wakil sekretaris jendral PKB dan Ahmad Basarah (PDIP). Dalam keseluruhan beritanya, Suara Merdeka tidak mencantumkan dari sumber lain, seperti politisi dari Partai Golkar (sendiri) atau lainnya. Argumentasi yang dijadikan landasan oleh Suara Merdeka adalah (1) pencalonan Joko Widodo sebagai capres tahun 2019 masih terlalu dini karena waktunya masih sangat lama, (2) yang terpenting sekarang ini adalah kerja untuk memenuhi janji-janjinya selama kampanye, 


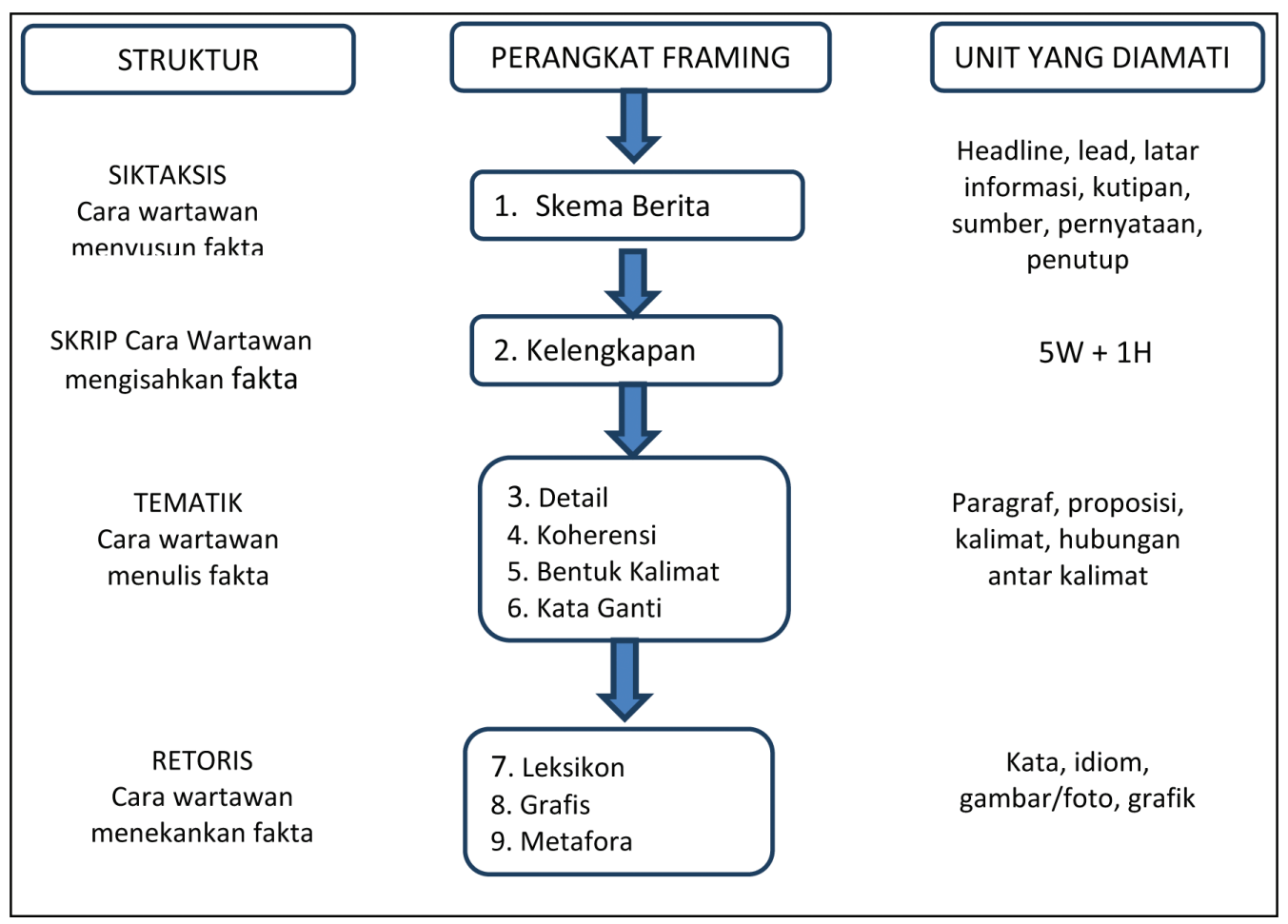

Bagan 1. Analisis Framing model Pan dan Kosicki

(3) dukungan Golkar tersebut ditengarahi "hanya" sebagai strategi untuk memperoleh kekuasaan dan untuk kepentingan jangka pendek, yaitu dalam rangka "mendongkrak" elektabilitas Partai Golkar yang terpuruk akibat masalah/kasus "papa minta saham", dan (4) dukungan Partai Golkar dinilai semu sifatnya yang patut dipertanyakan kebenarannya.

Dari sisi skrip, Suara Merdeka hanya menggali sumber dari dua politisi pendukung pemerintah, yaitu PKB dan PDIP. Kedua sumber ini dijadikan sumber satu-satunya sebagai bahan beritanya. Dari sisi tematik, Suara Merdeka hanya mengangkat tema yang pada intinya meragukan, menyalahkan, mempertanyakan kesungguhan Golkar terkait dengan pencalonan Joko Widodo sebagai capres tahun 2019 karena hal itu belum penting untuk dibicarakan. Terlalu dini, katanya. Selain itu, jika dilihat dari sisi kelengkapan berita $(5 \mathrm{~W} 1 \mathrm{H})$ sebagai mana tuntutan pemberitaan dinilai kurang lengkap. Hal itu,tampak dari tidak adanya penjelasan aspek dimana, kapan, siapa saja secara memadahi. Dilihat dari keberimbangan berita juga dinilai kurang. Secara ringkas disajikan dalam bentuk Tabel 1 .

\section{Frame Pencapresan Joko Widodo oleh Harian Kompas}

Kompas membuat frame gagal dankutukan terhadap Partai Golkar. Dari frame ini lalu, Kompas membuat tema berita tentang kegagalan Partai Golkar dalam mengkader. Karena itulah, Partai Golkar selalu gagal menjadikan kadernya menjadi RI-1. Sebagai contoh, Akbar Tanjung, Wiranto, Aburizal Bakri. Hal ini dikarenakan sistem pengkaderan ditubuh Partai Golkar yang tidak berjalan. Selain itu, patut disayangkan oleh sejumlah pihak, partai sebesar Golkar tidak mampu memberi warna dalam konstelasi politik ditingkat nasional. Oleh sebab itulah, Partai Golkar patut "dikutuk". Akibat kegagalan-kegagalan tersebutlah, lalu Partai Golkar akhirnya mencalonkan Joko Widodo sebagai calon presiden tahun 
Tabel 1. Frame Pencapresan Joko Widodo oleh Harian Suara Merdeka

\begin{tabular}{ll}
\hline ELEMEN & \multicolumn{1}{c}{ STRATEGI PENULISAN } \\
\hline Skematis & $\begin{array}{l}\text { Memaparkan dua politisi dari PKB dan PDIP melalui judul "Golkar Dinilai } \\
\text { Krisis Kader: Terlalu Dini Dukung Joko Widodo. }\end{array}$ \\
Skrip & $\begin{array}{l}\text { Partai Golkar dinilai terlalu dini mendeklarasikan dukungan terhadap Joko } \\
\text { Tematik }\end{array}$ \\
& $\begin{array}{l}\text { Widodo sebagai calon presiden untuk tahun 2019 } \\
\text { krisis kalonan Joko Widodo terlalu dini, (2) Pilpres masih jauh, (3) Golkar }\end{array}$ \\
& merebut simpati publik khususnya ke Pemerintah/Presiden Joko Widodo, (6) \\
Retoris & $\begin{array}{l}\text { Itulah (kehidupan) politik } \\
\text { Kalimat-kalimat yang digunakan bernada/bergaya memojokkan, menyalahkan, } \\
\text { menyayangkan Partai Golkar dengan mendeklarasikan Joko Widodo sebagai }\end{array}$ \\
& $\begin{array}{l}\text { capres yang akan datang melalui diksi: terlalu dini, pilpres masih jauh, itu hanya } \\
\text { strategi politik saja (untuk agar dapat jatah menteri), dukungan semu (karena } \\
\text { hanya di atas kertas) dan partai pendukung "pendatang baru". Berbeda dengan }\end{array}$ \\
& PKB dan PDIP yang sudah sejak awal mendukung pemerintah/Presiden Joko \\
Widodo (secara riil)
\end{tabular}

Tabel 2. Frame Pencapresan Joko Widodo oleh Harian Kompas

\begin{tabular}{|c|c|}
\hline ELEMEN & STRATEGI PENULISAN \\
\hline Skematis & $\begin{array}{l}\text { Memaparkan dua politisi dari PKB dan PDIP melalui judul "Golkar Dinilai } \\
\text { Krisis Kader: Terlalu Dini Dukung Joko Widodo. }\end{array}$ \\
\hline Skrip & $\begin{array}{l}\text { Partai Golkar dinilai terlalu dini mendeklarasikan dukungan terhadap Joko } \\
\text { Widodo sebagai calon presiden untuk tahun } 2019\end{array}$ \\
\hline Tematik & $\begin{array}{l}\text { (1) Pencalonan Joko Widodo terlalu dini, (2) Pilpres masih jauh, (3) Golkar } \\
\text { krisis kader, (4) hanya dukungan di atas kertas, (5) strategi Golkar untuk } \\
\text { merebut simpati publik khususnya ke Pemerintah/Presiden Joko Widodo, (6) } \\
\text { Itulah (kehidupan) politik }\end{array}$ \\
\hline Retoris & $\begin{array}{l}\text { Kalimat-kalimat yang digunakan bernada/bergaya memojokkan, menyalahkan, } \\
\text { menyayangkan Partai Golkar dengan mendeklarasikan Joko Widodo sebagai } \\
\text { capres yang akan datang melalui diksi: terlalu dini, pilpres masih jauh, itu hanya } \\
\text { strategi politik saja (untuk agar dapat jatah menteri), dukungan semu (karena } \\
\text { hanya di atas kertas) dan partai pendukung "pendatang baru". Berbeda dengan } \\
\text { PKB dan PDIP yang sudah sejak awal mendukung pemerintah/Presiden Joko } \\
\text { Widodo (secara riil) }\end{array}$ \\
\hline
\end{tabular}

2019. Hal ini dimaknai sebagai kegagalan Partai Golkar dalam mengkader kadernya, tetapi disisi lain Partai Golkar "haus kekuasaan", serta sangat bergantung pada pemeritah(an). Lebih jelasnya disajikan dalam bentuk Tabel 2.

\section{Frame Pencapresan Joko Widodo oleh Harian Republika}

Frame yang digunakan untuk membingkai Joko Widodo salah satunya dapat dibaca pada berita/teks tentang pencapresan Joko Widodo pada tahun 2019. Adalah partai Golkar yang mencalonkannya. Realitas ini lalu di-frame oleh Republika "hanya" dari sisi konvensi pencalonan. Seperti diketahui selama ini Partai Golkar menganut sistem konvensi dalam mencalonkan seorang calon presiden. Dari frame ini lalu dalam menyajikan berita, tidak di dalam harian Republika ditemukan satu kalimatpun yang menyinggung tentang kegagalan Partai Golkar dalam kaderisasi, kekrisisan kader yang 
handal dari tubuh Partai Golkar, apalagi soal "kutukan" terhadap Partai Golkar sebagaiamana ditemukan pada harian Suara Merdeka dan Kompas. Harian Republika hanya memberitakan secara detail pidato Joko Widodo selaku presiden dan pernyataan dukungan dari Partai Golkar sampai pemberian plakat dukungan tersebut ke Presiden Joko Widodo.

Untuk meneguhkan bahwa apa yang dilakukan Partai Golkar "benar" atau" tidak melanggar" (karena tidak melalui konvensi), diberitakanlah tentang produk/sumber dukungan tersebut dari Rapat Pimpinan Nasional (Rapimnas) Partai Golkar.
Dari frame ini pula, tema-tema yang diangkat oleh Republika adalah dukungan penuh dari semua unsur pimpinan yang resmi (Rapimnas), pernyataan Presiden Joko Widodo yang meminta konsistensi Partai Golkar dalam mendukung kebijakan Pemerintah agar program-program Pemerintah berjalan dengan baik, seperti pengampunan pajak dan program-program lainnya, misalnya program pembangunan infrastruktur, tol laut. Akibatnya, Republika "hanya" mengambil sumber berita dari Setyo Novanto dan Joko Widodo, serta Zulkifli Hasan, sehingga dari unsur pemberitaan $(5 \mathrm{~W} 1 \mathrm{H})$ kurang lengkap. Secara ringkas disajikan dalam Tabel 3.

Tabel 3. Frame Pencapresan Joko Widodo oleh Harian Republika

\begin{tabular}{|c|c|}
\hline ELEMEN & STRATEGI PENULISAN \\
\hline Skematis & $\begin{array}{l}\text { Melalui Rapat Pimpinan Nasional (Rapimnas), Partai Golkar mendukung Joko } \\
\text { Widodo sebagai calon presiden tahun 2019, meski hal ini baru dilakukan oleh } \\
\text { Partai Golkar sepanjang sejarah sejak lengsernya Soeharto. Sebab, tradisi } \\
\text { sebelumnya melalui sistem konvensi. }\end{array}$ \\
\hline Skrip & $\begin{array}{l}\text { Melalui forum resmi, yaitu Rapat Pimpinan Nasional (Rapimnas) ; Partai Golkar } \\
\text { mencalonkan Joko Widodo sebagai capres tahun 2019. Dukungan ini konkret } \\
\text { karena seluruh pimpinan (DPP, DPW, DPC) mendukung langkah Setyo } \\
\text { Novanto dengan diiringi tepuk tangan yang meriah. Bahkan dukungan itu } \\
\text { diperkuat dengan hadirnya Megawati, sejumlah menteri (Luhut), dan ketua MPR } \\
\text { dari PAN, Zulkifli Hasan. }\end{array}$ \\
\hline Tematik & $\begin{array}{l}\text { (1) Rapat Pimpinan Nasional (Rapimnas) Partai Golkar mendukung Joko } \\
\text { Widodo untuk dicalonkan sebagai calon presiden pada tahun 2019, (2) Semua } \\
\text { elemen/unsur pimpinan (DPP, DPW, DPC) mendukung pencalonan Joko } \\
\text { Widodo, (3) Partai Golkar secara resmi memberikan dukungan tersebut kepada } \\
\text { Joko Widodo sebagai calon presiden tahun 2019, (4) Wujud dan keseriusan } \\
\text { Partai Golkar mendukung Joko Widodo sebagai calon presiden tahun } 2019 \\
\text { ditandai dengan penyerahan plakat dukungan yang langsung diterima oleh Joko } \\
\text { Widodo (5) Presiden Joko Widodo dalam pidato sambutannya mengatakan } \\
\text { bahwa dukungan Partai Golkar terhadapnya konkret meskipun sebelumnya } \\
\text { merasa ragu atas pernyataan dukungan dari Partai Golkar, (5) Presiden Joko } \\
\text { Widodo berharap dukungannya serius, konsisten, dan konkret, (6) Kehadiran } \\
\text { tokoh-tokoh penting (Megawati, Zulkifli Hasan, Luhut, Ahok, dll.) dalam acara } \\
\text { Rapimnas Partai Golkar sebagai penanda koalisi baru ke dalam Koalisis } \\
\text { Indonesia Hebat (KIH) sehingga menjadi partai pendukung pemerintah. }\end{array}$ \\
\hline Retoris & $\begin{array}{l}\text { Kalimat-kalimat yang digunakan oleh harian Republika bernada mendukung } \\
\text { pencapresan Joko Widodo pada tahun 2019, disertai berita tentang tepuk tangan } \\
\text { meriah seluruh peserta Rapimnas. Secara grafis, Setyo Novanto dan pengurus } \\
\text { lainnya menunjukkan dukungan yang serius (dengan menyerahkan plakat) } \\
\text { kepada Presiden Joko Widodo. }\end{array}$ \\
\hline
\end{tabular}


Dengan mengambil contoh berita "Pencapresan Joko Widodo" yang dijadikan sampel data dalam tulisan ini dihasilkan (1) bahwa harian Suara Merdeka tidak mendukung langkah Partai Golkar karena diarasa/dinilai (2) akan mengancam posisi "nyaman", para partai pendukung pemerintah yang setia dan riil, yaitu PDIP, PKB, Nasdem, PPP yang selama ini tergabung dalam koalisi Koalisis Indonesia Hebat (KIH), (3) dukungan Partai Golkar dinilai semu karena "haus" kekuasaan, dan hanya untuk kepentingan atau syahwat politik Golkar jangka pendek, yaitu untuk meningkatkan elektabilitas Golkar, (4) Oleh karena itu, Presiden Joko Widodo diingatkan oleh partai pendukung setianya agar lebih baik fokus pada pekerjaan untuk mensejahterakan rakyat. Hal ini lebih penting untukmembuktikan/memenuhi janji-janjinya semasa kampanye dibandingkan menanggapi pencapresan dirinya oleh Partai Golkar. Untuk harian Kompas, terkait dengan pencapresan Joko Widodo lebih mem-frame bahwa: (1) di tubuh Partai Golkar telah terjadi krisis kader atau ketidakpercayaan diri pada ketersediaan kader yang ada. Hal ini terlihat, misalnya, dari pengalaman-pengalaman sebelumnya yang mencalonkan Akbar Tanjung, Wiranto, Aburizal Bakri yang gagal untuk menjadi/menduduki jabatan RI-1. Kegagalan yang beruntun menjadikan partai Golkar "trauma",(2) Oleh karena itu, diperlukan evaluasi secara komprehensif terhadap sistem pengkaderan, sistem kepemimpinan. Sebab, hal ini bisa jadi karena dalam kepengurusan Partai Golkar telah sering terjadi "perseteruan" di antara elit pimpinan partai, (3) kegagalan Partai Golkar selama ini tidak hanya disebabkan oleh sistem pengkaderan yang "macet", tetapi juga karena secara historis "ketergantungannya" pada pemerintah(an) alih-alih tidak mempunyai kemandirian dan keberanian untuk menjadi "oposisi". Selain itu, Partai Golkar dinilai haus kekuasaan. Sementara, harian Republika mem-frame Partai Golkar secara positif. Republika tidak mempersoalkan pencalonan Joko Widodo sebagai calon presiden pada tahun 2019 meskipun sebenarnya melanggar konvensi. Juga tidak memberitakan tentang "keburukan" Golkar, seperti (1) krisis kader, (2) kegagalan dalam sistem kaderisasi, (3) haus kekuasaan, (4) ketergantungannya pada pemerintah/ kekuasaan dan ke-oposisi-an yang selama ini dilakukan hanya "semu". Hal ini berbeda dengan kedua harian lainnya, yaitu Suara Merdeka dan Kompas.

Hasil penelitian ini juga menunjukkan bahwa diantara ketiga harian tersebut (Suara Merdeka, Kompas, dan Republika) terdapat peta ideologi yang berbeda. Dari perbedaan peta ideologi ini memunculkan perbedaan pada (1) aspek sintaksis, (2) skrip, (3) tematik, (4) dan retoris; akibat berikutnya tampak pada perbedaan (1) skema berita,(2) kelengkapan berita, (3) detail, dan (4) leksikon; akibat lainnya adalah terhadap kelengkapan unsur 5 W1 H (Suharyo, dkk. 2016).

\section{SIMPULAN}

Berdasarkan uraian hasil dan pembahasan secara umum dapat disimpulkan bahwa ketiga media tersebut, yaitu Suara Merdeka, Kompas, dan Republika berbeda dalam menyusun: (a) skema berita, (b) kelengkapan berita, (c) detail, (d) leksikon, dan (e) kelengkapan unsur 5W+ $1 \mathrm{H}$ dalam memberitakan Presiden Joko Widodo. Secara khusus diperoleh simpulan sebagai berikut. Pertama, Wartawan/ Media sebagai pihak yang mengkontruksi dengan hasil konstruksi: (a) Presiden Joko Widodo merespon keresahan yang terjadi di masyarakat, (b) Presiden Joko Widodo sosok yang tegas, (c) dalam mengambil keputusan, Presiden Joko Widodo sangat memperhitungkan dengan matang, dan (d) Presiden Joko Widodo dalam mengambil keputusan tidak berdasarkan pertimbangan yang matang dan tidak belajar dari masa lalu, dan (e) Presiden Joko Widodo 
belum mampu menangani masalah penggunaan narkoba dan korupsi. Kedua, Politisi sebagai pihak yang mengkontruksi dengan hasil konstruksi: (a) Presiden Joko Widodo tepat dalam mengambil keputusan, bertanggung jawab, dan berhasil dalam memimpin pemerintahannya, (b) dari oposisi, Presiden Joko Widodo dikonstruksikan sosok yang cerdik, tetapi yang dimaksud adalah secara negatif, dan (c) Program yang dijalankan hanya pencitraan semata. Ketiga, Pengamat/Pakar/ TokohMasyarakat sebagai pihak yang mengkontruksi dengan hasil konstruksi: (a) kepemimpinan Presiden Joko Widodo selama dua tahun terakhir mengalami kemajuan, dan (b) Presiden Joko Widodo gagal menjalankan program kerjanya.

\section{UCAPAN TERIMA KASIH}

Artikel ini merupakan bagian dari hasil penelitian RPP ( Riset Pengembangan dan Penerapan) tahun 2016. Oleh karena itu, pada kesempatan ini kami menyampaikan ucapan terima kasih kepada: (a) Rektor Universitas Diponegoro, Semarang, (b) Ketua Lembaga Penelitian dan Pengabdian kepada Masyarakat (LPPM) yang telah membiayai penelitian ini, (c) Dekan Fakultas Ilmu Budaya Universitas Diponegoro yang selalu mendorong penulis untuk terus giat menulis dan penelitian, dan (d) anggota tim peneliti yang telah bekerja dengan baik sehingga penelitian ini dapat terlaksana, (e) para kolega yang telah memberikan berbagai masukan yang sangat berharga, serta (f) kepada Narendra Dhanesywara Bayu Permadi yang telah ikut menjadikan artikel ini terwujud.

\section{DAFTAR PUSTAKA}

Atmadja, Xena Levina. 2014. "Analisis Framing terhadap Pemberitaan Sosok Basuki Tjahaja Purnama (Ahok) di Media Online". Surabaya: Universitas Kristen Petra.
Darma, Yose Aliah. 2013. Analisis Wacana Kritis. Bandung: Yrama Widya.

Eriyanto. 2012. Analisis Framing: Konstruksi, Ideologi, dan Politik Media (Cet. ke-3). Yogyakarta: LKIS.

Flora, Elina. 2014. "Analisis Framing Berita Calon Presiden RI 2014-2019 pada Surat Kabar Kaltim Post dan Tribun Kaltim". KalimantanTimur: Universitas Mulawarman.

Hallin, Daniel C. and Paolo Mancini. 1985. Speaking of the President. Dalam Michel Gurevitch and Mark R. Levy (ed). Mass Communication Review Yearbook. Vol.4.

Hasfi, Nurul. 2011. "Analisis Framing Pemberitaan Malinda Dee di Detikcom Majalah Tempo dan Metro TV". Semarang: Universitas Diponegoro.

Irfan, Noor. 2011. Analisis Framing Pemberitaan Harian Kompas Atas Ruuk-DIY. Semarang: Universitas Diponegoro.

Karman. 2013. "Media Massa dan Kontruksi realitas (Analisis framing terhadap Pemberitaan SKB tentang Ahamdiyah di Indonesia pada Surat Kabar Harian Suara Pembaruan dan Republika" dalam Jurnal Studi Komunikasi dan Media, Vol.17 (Juli-Desember 2013).

Lee, Blaine. 2002. The Power Principle (Terjemahan Alfin Saputra). Jakarta: Bina Putra Aksara.

Lukmantoro, Triyono. 2011. "Wacana Ahmadiyah di Media Massa (Analisis WacanaPemberitaan Harian Suara Merdeka dalam Kasus Penyerangan terhadap Jemaat Ahmadiyah Indonesiadi Cikeusik, Pandeglang, Banten)". Semarang: Universitas Diponegoro

Muslih, Masnur. 2008. "Kekuasaan Media Massa Mengonstruksi Realitas". Jurnal Bahasa dan Seni tahun 36 no. 2 Agustus 2008.

Prastyana, Prastyana. 2013. "Isu Majunya Joko Widodo sebagai Calon Gubernur DKI Jakarta di Media Massa (Analisis Framing Berita Seputar Isu Majunya 
Joko Widodo sebagai Calon Gubernur DKI Jakarta pada Harian Umum Solopos Periode Oktober 2011- Maret 2012)". Skripsi. Solo: UNS.

Putera, Ghanes Eka. 2014. Bingkai Media terhadap Pemberitaan Capres Joko Widodo pada Pilpres 2014 (Analisis Framing Media Online Kompas.Com dan Detik.Com). Semarang: Universitas Diponegoro.

Rachanca, Mahar. 2012. "Pembingkaian Koran Kompas dan Republika terhadap Peristiwa Perang Israel-Palestina". Semarang: Universitas Diponegoro.

Simbolon, Meydita. 2012. "KontruksiBerita dalam Media Massa (Analisis Framing Pemberitaan Dua Pasangan Calon Gubernur Dan Wakil Gubernur DKI Jakarta "Joko Widodo-Basuki dan Fauzi-Nachrowi" Dalam Majalah
Tempo)". Medan: Universitas Sumatera Utara.

Siregar, Tineke Kristina. 2013. "Sikap Harian Kedaulatan Rakyat terhadap Pemberitaan Kasus Penembakan di Lapas Cebongan". Semarang: Universitas Diponegoro.

Suharyo, dkk. 2016. "Konstruksi Media terhadap Presiden Joko Widodo melalui Analisis Framing". Semarang: Laporan Penelitian Universitas Diponegoro.

Windranuari, Satya. 2010. "Pembingkaian Kompas dan Suara Merdeka Mengenai Kontroversi Dana Talangan (Bail Out) Bank Century (Analisis Framing terhadap Pemberitaan Kompas dan Suara Merdeka)". Semarang: Universitas Diponegoro. 